\title{
The Effects of Screen Time and Social Media on Depressed Feelings and Suicidal Thoughts Among Undergraduates
}

\author{
Jeremy Evans ${ }^{1}$, Kassidy Smith ${ }^{1}$, Hailey Wimmenauer ${ }^{1}$ and Sharon Thompson ${ }^{1}$ \\ ${ }^{1}$ Coastal Carolina University, Conway, SC, USA \\ DOI: https://doi.org/10.47611/jsr.v10i1.1170
}

\begin{abstract}
$\underline{\text { ABSTRACT }}$
Beginning around 2011, there have been increases in mental health issues among teens and young adults. A possible reason for this rise has been the growth of social media through electronic communication; therefore, this study examined social media usage and suicide among undergraduates. An online survey was developed and after Institutional Review Board approval, was completed by 506 undergraduates (67.9\% female, 32.1\% male) at 23 southeastern and midwestern higher education institutions. Among these undergraduates, it was found that $24 \%$ thought about suicide in the past year and $4.2 \%$ had actually attempted to kill themselves. Those who considered killing themselves in the past year were significantly more likely to feel the need to compare themselves to others when browsing social media $(\mathrm{p}<.0001)$, felt their life was worse than others based on what they saw on social media $(\mathrm{p}<.0001)$, and had feelings of sadness or suicidal thoughts after browsing social media $(\mathrm{p}<.0001)$ compared to those who had not thought of suicide. Undergraduates who had attempted suicide in the past year were more likely to feel their self-image was negatively affected by interaction with social media websites $(\mathrm{p}<.05)$ and also had feelings of sadness or suicidal thoughts after browsing social media $(\mathrm{p}<.05)$ compared to those who had not attempted suicide. Females were more likely than males to report negative effects of browsing social media $(\mathrm{p}<.001)$. These significant associations between suicidal thoughts and social media usage should be studied further to better devise health education and advocacy campaigns among this population.
\end{abstract}

\section{Introduction}

\section{Mental Health}

Mental health includes a plethora of different feelings, behaviors, and emotions. It is defined as an individual's emotional, psychological, and social well-being (United States Department of Health and Human Services [USDHHS], 2017). Genetics, environment, lifestyle, and many other factors come into play with each individual's state of mental health.

Depression and suicide are two areas that fall under the mental health umbrella. Depression is defined as a mood disorder that affects the brain and includes symptoms such as intense feelings of sadness, energy loss, and thoughts of death or suicide (USDHHS, 2017). Oftentimes, depression serves as a mood disorder that leads to suiciderelated behaviors. Suicide is the intentional taking of one's own life and a suicide attempt is when the act or instance of taking one's own life does not result in death but only results in self-harm (Gregory, 2020). Occurrences of mental health disturbances are high among adults. In 2016, 44.7 million adults were diagnosed with a mental health disorder 
(Substance Abuse and Mental Health Services Administration [SAMHSA], 2017). Depression and suicidal tendencies are among those.

\section{United States}

Researchers have reported that $19.1 \%$ of U.S. adults experienced mental illness in 2018 , 47.6 million people, representing roughly 1 in 5 adults (SAMSHA, 2017). Rates of depression and suicide are both on the rise in our country. According to the 2015 National Survey on Drug Use and Health, 1 out of 13 people, approximately 2.9 million individuals, aged 18 to 25 years noted suicidal thoughts (cited by Center for Behavioral Health Statistics and Quality, 2016). It should be noted that this is only in reference to reported cases, excluding those that were not diagnosed or confirmed. In 2017, reports show the total rates of suicide have increased by $31 \%$ in the last 16 years (National Institute of Mental Health [NIMH], 2019). In addition, it is known that many different experiences might play a role in these mental health struggles. For example, how people are spending their spare time has evolved over the years and could be impactful, especially with the introduction of technology.

\section{Screen time and Social media}

\section{United States}

While technology can be a very useful tool, it can affect an individual's mental health in a positive or negative way. According to the Australia Health Survey (South Australia Government, 2007), "screen time is defined as the amount of time spent watching TV, including videos and DVDs, playing computer games on video consoles, on a mobile device, or on a computer and using computers for other purposes," (p. 6). In today's technology rich society, a common form of screen time use being focused on is that of social media.

Social media is defined as the use of screen time exclusively to communicate and interact with individuals through the use of different social platforms (South Australia Government, 2007). The norms of using social media have grown exponentially to the point where it is how billions of people stay connected and get world information daily ("The impact of social media," 2019). A few examples of social media platforms include Facebook, Twitter, Instagram, Snapchat, and LinkedIn. According to Smith and Anderson (2018), 88\% of adults aged 18 to 29 are using some form of social media. Similarly, it was found that $78 \%$ of 18 to 24 -year-olds are using Snapchat, $71 \%$ are using Instagram, 45\% are using Twitter, and 94\% are using YouTube (Smith \& Anderson, 2018). Researchers also reported that this has increased significantly in the last decade (Perrin, 2015). In 2005, only 12\% of young adults reported using at least one social networking site. A decade later, in 2015, 90\% of young adults reported using at least one social networking site (Perrin, 2015). Just recently, researchers have noted "Social media and networking platforms have replaced schools and playgrounds as the places where our children spend the majority of their time" (Odgers et al., 2020, p. 498). It is clear that social media has evolved to include many different platforms which are used at very high levels among young adults.

\section{Screen time and Mental Health}

Other investigators have been curious about this steep increase in technology use and the effects of spending time staring at a screen. Results thus far have indeed found that increased screen time is negatively affecting mental health. For example, Twenge et al. (2018), found that spending 5+ hours online a day compared to less than 1 hour increased the likelihood of having at least one suicide risk factor by $71 \%$. Internet addiction was found by researchers to be extremely high and the leading cause of depression, anxiety, and stress (Gupta et al., 2018). Boers and colleagues (2020) research found that increases in anxiety among adolescents are associated with increased use of social media, television, and computers. Lastly, the frequency of social media use has been found to be associated with alcohol, tobacco, and other drug use and depressive symptoms (Ilakkuvan et al., 2018). As a result of these findings, the effects 
of screen time and social media on mental health needs to be studied further; therefore, the purpose of this research study was to examine rates of depressed feelings, thoughts about suicide, and how these may correlate with screen time use among undergraduates.

\section{Methods}

The Breaking Suicide and Depression (SAD) Survey was developed in paper-pencil and online formats using items from The Social Media Experiences Survey (Kettle et al., 2016), The HELENA Screen-Time Based Sedentary Behavior Questionnaire (Rey-López et al., 2012), The Center for Epidemiologic Studies Depression Scale-Revised (CESD-R-10) (Eaton et al., 2004), The Suicide Behaviors Questionnaire-Revised (SBQ-R) (Osman et al., 2001), as well as items to determine demographic information.

The final survey received approval by the university's Institutional Review Board, was anonymous, and was formatted for online and print distribution. In the Spring of 1999 the survey was promoted via links on various webpages, as well as through QR codes, email distribution and Facebook to undergraduate students at higher education institutions across the southeast and midwest to complete. Data were analyzed with JMP software using frequencies, means, correlations, Chi square tests, and Analysis of Variance (ANOVA) testing. A p-value of $<.05$ was required for statistical significance.

\section{Results}

Surveys were completed by undergraduates from 20 higher education institutions $[\mathrm{N}=561$; Female $=67.9 \%$; Average $\mathrm{Age}=20-29]$. Number of responses $[\mathrm{N}]$ may vary due to some participants abstaining from answering selected responses.

\section{Social media and Screen time use}

Using items from the HELENA Screen-time Based Sedentary Questionnaire (Rey-López et al., 2012), participants reported most screen time was spent using social media. In order to determine the average amount of time spent on social media, participants were asked to choose between less than 3 hours, 3-4 hours, and 4 or more hours of social media screen time for both weekdays and weekends. The highest percentages of time spent on social media for all participants on weekdays was 1 to 2 hours at $33.59 \%$ and 3 to 4 hours on weekends at $30.83 \%$. Chi-squared tests revealed differences by sex for weekday $[\mathrm{X} 2(5, \mathrm{~N}=521)=41.45, \mathrm{p}<0.0001]$, and for weekend social media use [X2 $(5, \mathrm{~N}=519)=36.6, \mathrm{p}<0.0001]($ see Table 1$)$.

Table 1. Responses by sex for social media screen time use on weekdays and weekends.

\begin{tabular}{|c|c|c|c|c|}
\hline Time of Week & Sex & $<\mathbf{3}$ Hours & $\mathbf{3 - 4}$ Hours & 4+ Hours \\
\hline Weekdays* & Female & $49.5 \%$ & $28.6 \%$ & $21.8 \%$ \\
\cline { 2 - 5 } $\mathrm{N}=521$ & Male & $67.8 \%$ & $17.8 \%$ & $14.2 \%$ \\
\hline Weekends** & Female & $36.7 \%$ & $33.0 \%$ & $30.2 \%$ \\
\cline { 2 - 5 }$=519$ & Male & $56.5 \%$ & $30.8 \%$ & $17.2 \%$ \\
\hline
\end{tabular}

$*\left[\mathrm{X}^{2}(5, \mathrm{~N}=521)=41.45, \mathrm{p}<0.0001\right]$

$* *\left[\mathrm{X}^{2}(5, \mathrm{~N}=519)=36.6, \mathrm{p}<0.0001\right]$

The beliefs undergraduates had about their personal social media screen time use was examined using a Likert scale [1-Never; 4-Often] and the top 5 mean scores of the 9 total items on the social media survey are provided (see Table 2). 
Table 2. Top five mean scores for social media belief items.

\begin{tabular}{|c|c|}
\hline Social Media Survey Items & Mean \\
\hline Feeling happier after getting “likes” on your social media posts $(N=556)$. & 2.70 \\
\hline Continuously checking how many “likes” your post gets after posting on social media $(N=556)$. & 2.68 \\
\hline Feeling the need to compare yourself to others when browsing social media $(N=557)$. & 2.55 \\
\hline Feeling like your own self-image is positively affected by your interaction with various social media & 2.39 \\
\hline Feelingsites $(N=548)$. & 2.20 \\
\hline
\end{tabular}

Note: $1=$ Never; $4=$ Often

Participants responded with the highest mean scores for: "Feeling happier after getting 'likes' on your social media posts" ( $M=2.70, N=556)$. The remaining top 4 are as follows: "Continuously checking how many 'likes' your post gets after posting on social media" $(\mathrm{M}=2.68, \mathrm{~N}=556)$, "Feeling the need to compare yourself to others when browsing social media" ( $\mathrm{M}=2.55, \mathrm{~N}=557)$, "Feeling like your own self-image is positively affected by your interaction with various social media website" ( $\mathrm{M}=2.39, \mathrm{~N}=548)$, and "Feeling like your life is worse than others based on what you see on social media" $(\mathrm{M}=2.20, \mathrm{~N}=557)$.

\section{Suicidal thoughts/behavior}

An analysis of selected items from the related SBQ-R (2001) was used, and ANOVA tests were performed by sex $[\mathrm{N}=554]$. No significant differences were found by sex for each of these items related to suicidal thoughts and behavior: "Have you ever thought about or attempted to kill yourself?", "How often have you thought about killing yourself in the past year?", or "How likely is it that you will attempt suicide one day?".

For the item, "Have you ever thought about or attempted to kill yourself?", 1.8\% responded "yes" (Male: $\mathrm{N}=5$; Female: $\mathrm{N}=5$ ). For the item "How often have you thought about killing yourself in the past year", $9.6 \%$ responded they had at least once (Male: $\mathrm{N}=29$; Female: $\mathrm{N}=24$ ). Finally, for the item "Will you attempt suicide in the future", 2.3\% responded "yes" (Male: N=8; Female: N=5). See Figure 1 for the number of responses by sex for this item.

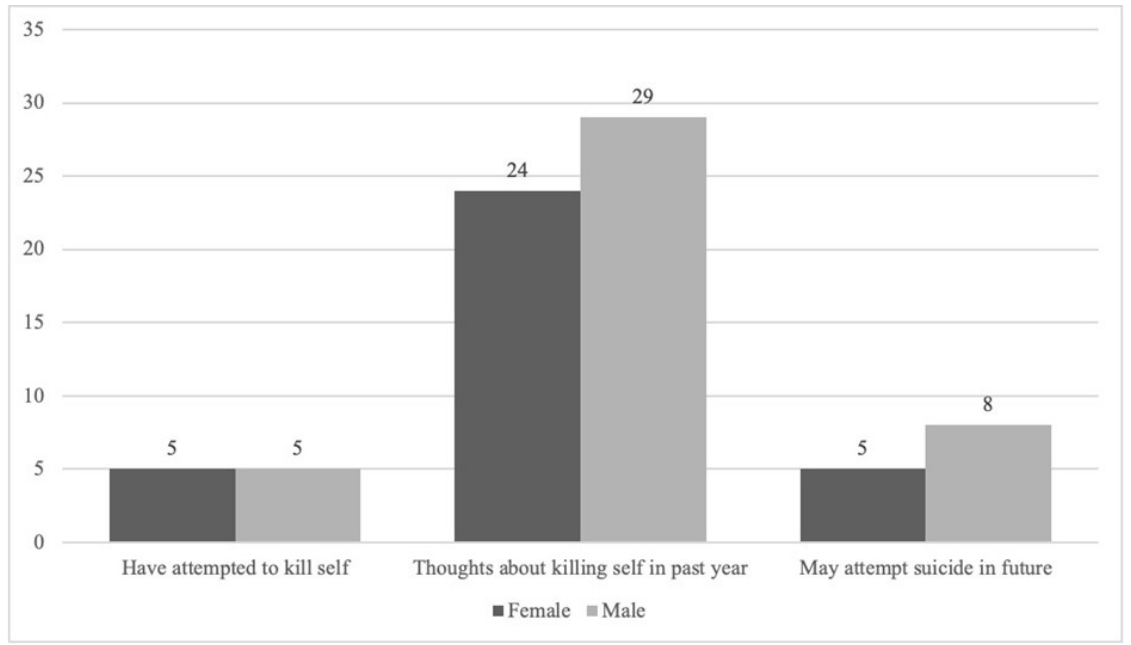

Figure 1. Number of responses for suicidal thoughts and behaviors by sex $(\mathrm{N}=554)$. 
Thoughts about suicide were next examined using ANOVA tests to determine the difference between those who had thought about killing themselves one or more times in the past year (OM - one or more times) and those who had no suicidal thoughts in the past year (NT - no thoughts). The participants were asked to rate their experiences in relation to the selected questions on a Likert scale [1-Never; 4-Often] and ANOVA testing was performed comparing OM and NT responses. Participants were asked to rate their feelings for the following questions: "Feeling the need to compare yourself to others when browsing social media" [N=552; OM=2.91, $\mathrm{NT}=2.44 ; \mathrm{p}<0.0001]$, "Feeling sad after not getting 'likes' on your social media posts" [N=551; $\mathrm{OM}=2.24, \mathrm{NT}=1.93 ; \mathrm{p}<0.01]$, "Feeling like life is worse than others based on what you see on social media websites" [ $\mathrm{N}=552 ; \mathrm{OM}=2.64, \mathrm{NT}=2.06 ; \mathrm{p}<0.0001]$, "Feeling like your own self-image is negatively affected by your interaction with various social media websites" [N=547; OM=2.43, $\mathrm{NT}=1.88 ; \mathrm{p}<0.0001]$, "Having feelings of sadness or suicidal thoughts after browsing social media websites" $[\mathrm{N}=551 ; \mathrm{OM}=1.84, \mathrm{NT}=1.23 ; \mathrm{p}<0.0001]$, and "Finding yourself spending an excess amount of time viewing other profiles of people or friends you 'admire"” [N=549; OM=2.57, NT=2.11; p < 0.0001] (see Table 3).

Table 3. Responses for social media belief items by thoughts about suicide.

\begin{tabular}{|c|c|c|}
\hline Survey item & Mean & p-value \\
\hline \multirow{2}{*}{$\begin{array}{l}\text { Feeling the need to compare yourself to others when browsing social media }(N=552) \text {. } \\
\qquad \begin{array}{c}\text { Never thought about killing self in past year } \\
\text { Thought of killing self - one or more times }\end{array}\end{array}$} & 2.44 & \\
\hline & 2.91 & $\mathrm{p}<.0001$ \\
\hline \multirow{2}{*}{$\begin{array}{c}\text { Feeling sad after not getting "likes" on your social media posts }(N=551) \text {. } \\
\text { Never thought about killing self in past year } \\
\text { Though of killing self - one or more times }\end{array}$} & 1.93 & \\
\hline & 2.24 & $\mathrm{p}<0.01$ \\
\hline \multirow{2}{*}{$\begin{array}{l}\text { Feeling like life is worse than others based on what you see on social media websites } \\
\qquad(N=552) \text {. } \\
\text { Never thought of killing self in past year } \\
\text { Though of killing self - one or more times }\end{array}$} & 2.06 & \\
\hline & 2.64 & $\mathrm{p}<0.0001$ \\
\hline \multirow{2}{*}{$\begin{array}{l}\text { Feeling like you own self-image is negatively affected by your interactions with various so- } \\
\text { cial media websites }(N=547) \text {. } \\
\text { Never thought of killing self in past year } \\
\text { Though of killing self - one or more times }\end{array}$} & 1.88 & \\
\hline & 2.43 & $\mathrm{p}<0.0001$ \\
\hline \multirow{2}{*}{$\begin{array}{l}\text { Having feelings of sadness or suicidal thoughts after browsing sc } \\
\qquad \begin{array}{r}(N=551) \text {. } \\
\text { Never thought of killing self in past year } \\
\text { Though of killing self - one or more times }\end{array}\end{array}$} & 1.23 & \\
\hline & 1.84 & $\mathrm{p}<0.0001$ \\
\hline \multirow{2}{*}{$\begin{array}{l}\text { Finding yourself spending an excess amount of time viewing other profiles of people or } \\
\text { friends you "admire" }(N=549) \text {. } \\
\text { Never thought of killing self in past year } \\
\text { Though of killing self - one or more times }\end{array}$} & 2.11 & \\
\hline & 2.57 & $\mathrm{p}<0.0001$ \\
\hline
\end{tabular}

These results indicate that those undergraduates who reported suicidal thoughts one or more times in the past year were more likely to report negative effects from social media use compared to those who have not had these thoughts. 


\section{Depression}

In order to learn more about correlations between depression and screen time usage, questions derived from the Center for Epidemiological Studies Depression Scaled - Revised (CESD-R-10) were used (Eaton et al., 2004). Participants were asked to answer the depression questions using a Likert Scale [1-Never; 4-Often]. Participants were first asked how many days in the past week they felt depressed. It was found that $85.14 \%$ of participants responded: "Rarely or never depressed -2 days or less" ( $\mathrm{N}=424)$, and $14.86 \%$ responded: "Occasionally or most of the time -3 or more days this past week" ( $\mathrm{N}=74)$ (see Table 4).

Table 4. Responses to "I felt depressed in the past week" ( $\mathrm{N}=498)$.

\begin{tabular}{|c|c|}
\hline Survey Response to "I felt depressed in the past week" & Percentage of Participants \\
\hline Rarely or never (2 days or less) & $85 \%$ \\
\hline Occasional of most (3 or more days) & $15 \%$ \\
\hline
\end{tabular}

Using Pearson Correlation coefficients, significant correlations were found for participant answers to the question "I felt depressed this past week" and the following survey items: "Feeling the need to compare yourself to others when browsing social media" $[\mathrm{r}(496)=0.2488 ; \mathrm{p}=<0.0001 ; \mathrm{p}<0.0001]$, "Feeling like life is worse than others based on what you see on social media websites" $[\mathrm{r}(496)=0.3583 ; \mathrm{p}=<0.0001 ; \mathrm{p}<0.0001]$, "Continuously checking how many 'likes' your post gets after posting on social media" $[\mathrm{r}(496)=0.1219 ; \mathrm{p}=0.0065 ; \mathrm{p}<0.01]$, "Feeling happier after getting 'likes' on your social media posts" $[\mathrm{r}(496)=0.1113 ; \mathrm{p}=0.013 ; \mathrm{p}>0.01]$, and "Feeling like your own selfimage is negatively affected by your interaction with various social media websites" $[\mathrm{r}(495)=0.3374 ; \mathrm{p}=<0.0001 ; \mathrm{p}<$ 0.0001] (see Table 5).

Table 5. Responses to social media belief items that were correlated with "I felt depressed in the past week".

\begin{tabular}{|c|c|c|c|}
\hline $\begin{array}{c}\text { Survey Responses } \\
\text { Feeling the need to compare yourself to others when browsing social } \\
\text { media (N=497). }\end{array}$ & 2.57 & .25 & $\mathrm{p}<0.0001$ \\
\hline $\begin{array}{c}\text { Feeling like life is worse than others based on what you see on social } \\
\text { media websites }(N=503) \text {. }\end{array}$ & 2.20 & .36 & $\mathrm{p}<0.0001$ \\
\hline $\begin{array}{c}\text { Continuously checking how many "likes" your post gets after posting on } \\
\text { social media (N=503). }\end{array}$ & 2.69 & .12 & $\mathrm{p}<0.01$ \\
\hline $\begin{array}{c}\text { Feeling happier after getting “likes" on your social media posts } \\
\text { (N=503). }\end{array}$ & 2.73 & .11 & $\mathrm{p}<0.01$ \\
\hline $\begin{array}{c}\text { Feeling like your own self-image is negatively affected by your interac- } \\
\text { tion with various social media websites }(N=502) .\end{array}$ & 2.03 & .34 & $\mathrm{p}<0.0001$ \\
\hline
\end{tabular}

Note: $1=$ Never; $4=$ Often

The question "I felt depressed" was significantly correlated with the following items: "How often have you had feelings of sadness or suicidal thoughts after browsing social media websites" $[\mathrm{r}(496)=0.5167 ; \mathrm{p}=<0.001 ; \mathrm{p}<$ 0.0001], "How often do you find yourself spending an excess amount of time viewing other profiles of people or friends you 'admire" $[\mathrm{r}(495)=0.2313 ; \mathrm{p}=0.23 ; \mathrm{p}<0.0001]$, and "How much time do you spend on weekends browsing social media sites" $[\mathrm{r}(491)=0.1081 ; \mathrm{p}=0.016 ; \mathrm{p}>0.01]$ (see Table 6). 
Table 6. Responses to items involving suicidal thoughts and social media beliefs that were correlated with "I felt depressed in the past week".

\begin{tabular}{|c|c|c|c|}
\hline Survey Items & Mean & r & p-value \\
\hline $\begin{array}{c}\text { How often have you had feelings of sadness or suicidal thoughts } \\
\text { after browsing social media websites (N=503). }\end{array}$ & 1.37 & .52 & $\mathrm{p}<0.0001$ \\
\hline $\begin{array}{c}\text { How often do you find yourself spending an excess amount of } \\
\text { time viewing other profiles of people or friends you "admire" } \\
(N=502) .\end{array}$ & 2.25 & .23 & $\mathrm{p}<0.0001$ \\
\hline $\begin{array}{c}\text { How much time do you spend on weekends browsing social me- } \\
\text { dia sites (N=499). }\end{array}$ & 4.58 & .11 & $\mathrm{p}>0.01$ \\
\hline
\end{tabular}

Note: $1=$ Never; $4=$ Often

To summarize, as feelings of depression increased among undergraduates, reports of negative impacts from social media use also increased.

\section{Discussion}

\section{Social media/Screen time use}

The HELENA Questionnaire helped show the beliefs undergraduates have about their own screen time/social media usage. Comparing the data by sex, it is shown that females tend to spend more time on social media during both weekdays and weekends. Simón et al. (2019) found similar sex differences in their study which reported that on average, females reported spending 143.09 minutes a day on their mobile device during the weekdays and 206.12 minutes during the weekends compared to males who spent an average of 117.20 minutes during the weekdays and 163.26 minutes during the weekends. Our results indicate that females spent between 1-2 and 3-4 hours on social media during weekdays and weekends while males spent an average between 30 minutes-1 hour and 1-2 hours, respectively.

The top five belief items showed that many participants feel their mental state and self-esteem can be affected by either the amount of "likes" a post can get, or by viewing other profiles of people they "admire". In today's society these feelings could continue to increase since social media is becoming even more popular.

\section{Suicidal thoughts/behavior}

Before survey distribution it was hypothesized that responses for thoughts about suicide within the past year would be low; however, they were at roughly $2 \%$ for each item, which was higher than expected. While this number may seem low, it is impactful when looking at suicidal thoughts. With available resources and the potential of early warning signs, the hope is that the percentage could be lower.

Sex differences were analyzed using ANOVA tests. Results revealed no significant differences for suicidal thoughts and behaviors by sex. Conversely, Zhang et al. (2019), found that suicidal ideation among high school aged participants was significantly different by sex. They reported that girls had a $13.3 \%$ ideation rate while boys had a $10.7 \%$ ideation rate.

When comparing responses to social media items between participants who had no suicidal thoughts in the past year (NT) and those who had one or more suicidal thoughts in the past year (OM), significant differences were found. On average, those who had one or more suicidal thoughts in the past year reported experiencing negative social media items more frequently. 


\section{Depression}

Results within this study are similar to those recently reported by researchers whereby they found associations between social media usage and depression among adolescents (Boers, Afzali, \& Newton, 2019). The significant correlations found between depression and social media beliefs indicates that action might be considered to make social media a more positive platform for young adults. When comparing thoughts and experiences of depression with suicidal thoughts, there were also significant correlations found for each of the items. It can be said that when a large amount of time is spent on social media, feelings of depression and suicidal thoughts have a higher probability of occurring among undergraduates. Suicidal thoughts could also be affected by an individual's mood; therefore, social media use could make these feelings worse in that moment rather than cause the suicidal thoughts. Determinants of these effects are beyond the scope of this study.

\section{Screen time and Mental Health}

These findings yielded similar results as those found in previous research. For example, increased amounts of screen time and social media use showed a direct correlation to increased suicidal thoughts and behaviors (Twenge et al., 2018). Additionally, increased social media use was associated with depression and our data showed the same correlations (Gupta et al., 2018; Ilakkuvan et al., 2018). Overall, consistent findings indicate the effects of social media usage on negative mental health tendencies.

\section{Limitations}

Limitations of this study could impact the results found. Some limitations could be participants omitting questions, leading to potentially down-played responses due to the mental health stigma. Although the survey was anonymous and participants were given the option to skip questions within the survey if they did not feel comfortable answering them, some responses may be skewed. There is still a large stigma around mental health and a lot of people are not comfortable talking about it. This may impact participants' willingness to answer truthfully. Lastly, our survey was just a quick moment in time for the participants and how they were feeling at that particular time could be very different from their other day-to-day experiences.

\section{Conclusion}

According to these findings, we believe that social media and screen time may influence the mental health of undergraduate students, especially given the astronomical increases in technology. Education and advocacy campaigns may be a viable plan of action on university campuses so that young adults can be taught the possible negative effects of screen time use on mental health. In addition, advocacy for healthy technology practices should be implemented in order to better equip these young adults to positively influence their mental health. It is recommended that the relationship between social media screen time use on suicidal thoughts and feelings of depression be further studied among other age groups and populations. 


\section{References}

Boers, E., Afzali, M., \& Conrod, P. (2020). Temporal associations of screen time and anxiety symptoms among adolescents. Canadian Journal of Psychiatry, (65)3, 206-208.

Boers, E., Afzali, M. \& Newton, N. (2019). Association of screen time and depression in adolescence. Journal of American Medical Association Pediatrics, 173(9), 853-859.

Center for Behavioral Health Statistics and Quality. (2016). 2015 National Survey on Drug Use and Health: Methodological summary and definitions. Retrieved from https://www.samhsa.gov/data/sites/default/files/NSDUHDetTabs-2015/NSDUH-DetTabs-2015/NSDUH-DetTabs-2015.pdf

Eaton, W.W., Muntaner, C., Smith, C., Tien, A., \& Ybarra, M. (2004). Center for Epidemiologic Studies Depression Scale: Review and revision (CESD and CESD-R). In: Maruish ME, ed. The Use of Psychological Testing for Treatment Planning and Outcomes Assessment. 3rd ed. Mahwah, NJ: Lawrence Erlbaum:363-377.

Gregory, C. (2020, March 2). Suicide and suicide prevention: Understanding the risk factors, prevention and what we can do to help. Psychom. https://www.psycom.net/depression.central.suicide.html

Gupta, A., Khan, A.M., Rajoura, O.P. \& Srivastava, S. (2018). Internet addiction and its mental health correlates among undergraduate college students. Journal of Family Medicine and Primary Care, 7(4),721-727. doi:

10.4103/jfmpc.jfmpc_266_17

Ilakkuvan, V., Johnson, A., Villanti, A.C., Evans, W.D. \& Turner, M. (2018). Patterns of social media use and their relationship to health risks among young adults. Journal of Adolescent Health, 64(2), 158-164.

https://doi.org/10.1016/j.jadohealth.2018.06.025

Kettle, P., Gilmartin, N., Corcoran, M. P., Byrne, D., \& Sun, T. H. (2016, December). Time Well Spent? A survey of student online media usage. Retrieved from https://www.maynoothuniversity.ie/sites/default/files/assets/docu$\underline{\text { ment/SOCIAL MEDIA SURVEY FINALV 1.pdf }}$

National Institute of Mental Health. (2019, April). Suicide. https://www.nimh.nih.gov/health/statistics/suicide.shtml

Odgers, C., Schueller, S., \& Ito, M. (2020). Screen time, Social media use, and adolescent development. Annual Review of Developmental Psychology, 2, 485-502.

Osman, A., Bagge, C.L., Guitierrez, P.M., Konick, L.C., Kooper, B.A. \& Barrios, F.X. (2001). The Suicidal Behaviors Questionnaire-Revised (SBQ-R): Validation with clinical and nonclinical samples. Assessment.

Perrin, A. (2015, October 8). Social media usage: 2005-2015. Retrieved from https://www.pewresearch.org/internet/2015/10/08/social-networking-usage-2005-2015/

Rey-López, J.P., Ruiz, J.R., \& Ortega, F.B., et al. (2012). Reliability and validity of a screen time-based sedentary behaviour questionnaire for adolescents: The HELENA study. European Journal of Public Health, (3), 373-377. DOI: $10.1093 /$ eurpub/ckr040. 
Simón, L., Aibar, A., García-González, L., Abós, A., \& Sevil, J. (2019). "Hyperconnected” adolescents: Sedentary screen time according to gender and type of day. European Journal of Human Movement, 43, 49-66.

Smith, A., \& Anderson, M. (2018, March 1). Social media use in 2018. Retrieved from https://owl.purdue.edu/owl/research and citation/apa6 style/apa formatting and style guide/reference list electronic sources.html

South Australia Government. (2007). National Australian children's nutrition and physical activity survey. South Australian Findings. https://www.health.gov.au/internet/main/publishing.nsf/Content/8F4516D5FAC0700ACA257BF0001E0109/\$File/childrens-nut-phys-survey.pdf

Substance Abuse and Mental Health Services Administration. (2017). Key substance use and mental health indicators in the United States: Results from the 2016 national survey on drug use and health. Retrieved from https://www.samhsa.gov/data/sites/default/files/NSDUH-FFR1-2016/NSDUH-FFR1-2016.htm

Twenge, J. M., Joiner, T. E., Rogers, M. L., \& Martin, G. N. (2018). Increases in depressive symptoms, suicide-related outcomes, and suicide rates among U.S. adolescents after 2010 and links to increased new media screen time. Clinical Psychological Science, 6(1), 3-17. doi:10.1177/2167702617723376

The impact of social media: Is it irreplaceable? (2019, July 26). Knowledge at Wharton. Retrieved April 10, 2020, from https://knowledge.wharton.upenn.edu/article/impact-of-social-media/

United States Department of Health and Human Services. (2017). Depression. Retrieved from https://www.mentalhealth.gov/basics/depression

Zhang, Y., Lei, Y., Song, Y., Lu, R., Duan, J., \& Prochaska, J.J. (2019). Gender differences in suicidal ideation and health-risk behaviors among high school students in Beijing, China. Journal of Global Health, 9(1). doi:

10.7189/jogh.09.010604 